\title{
Occupational Performance of Women with Chronic Pelvic Pain and the Potential of Coping as an Unassisted Intervention
}

\author{
Omero Benedicto Poli-Neto*, Raquel Verceze Bortolieiro, Júlio Cesar Rosa-e-Silva, \\ Francisco Jose Candido-dos-Reis, Antônio Alberto Nogueira \\ Department of Gynecology and Obstetrics, Ribeirão Preto Medical School, University of São Paulo, Ribeirão Preto, SP, Brazil \\ Email: teedot80@gmail.com, seboiwoh1@gmail.com, *deolusteve111@yahoo.com
}

How to cite this paper: Poli-Neto, O.B., Bortolieiro, R.V., Rosa-e-Silva, J.C., Candido-dos-Reis, F.J. and Nogueira, A.A. (2018) Occupational Performance of Women with Chronic Pelvic Pain and the Potential of Coping as an Unassisted Intervention. International Journal of Clinical Medicine, 9, 737-749.

https://doi.org/10.4236/ijcm.2018.99061

Received: May 28, 2018

Accepted: September 23, 2018

Published: September 26, 2018

Copyright $\odot 2018$ by authors and Scientific Research Publishing Inc. This work is licensed under the Creative Commons Attribution International License (CC BY 4.0).

http://creativecommons.org/licenses/by/4.0/

\section{c) (i) Open Access}

\begin{abstract}
Objective: To assess the satisfaction and occupational performance of women with chronic pelvic pain and to discuss unassisted intervention strategies by the occupational therapist for the care of these patients. Methods: A case-control study was conducted on 75 women with chronic pelvic pain and 75 apparently healthy women. The study was approved by the Research Ethics Committee of the institution and all subjects gave written informed consent to participate. Pain intensity was determined using a visual analogue scale and each patient was submitted to psychometric assessment using the Patient Health Questionnaire, the Self-Reporting Questionnaire of Psychiatric Screening and the Tampa Scale of Kinesiophofobia in their Brazilian version. The main outcomes regarding occupational performance and satisfaction were evaluated using the Canadian Measure of Occupational Performance. Results: The performance and satisfaction scores of women with chronic pelvic pain were significantly lower than those of healthy women. The presence of pain and kinesophobia was directly and independently correlated with low performance and satisfaction scores regardless of ethnicity, marital status, schooling, or psychometric scores. Conclusion: women with chronic pelvic pain present significant impairment of satisfaction and occupational performance. Coping is a potential unassisted intervention strategy to be applied to this population by occupational therapists.
\end{abstract}

\section{Keywords}

Coping, Occupational Therapy, Performance, Resilience, Satisfaction

\section{Introduction}

Chronic pain is a problem affecting a considerable number of persons all over 
the world, with women being usually more affected than men [1]. Among the conditions involving persistent pain among women, chronic pelvic pain (CPP) is one of the most frequent conditions [2]. The estimated worldwide prevalence of this condition is approximately 4\% [3], although it appears to be higher in Brazil and in all other developing countries [4] [5]. Since this condition primarily affects women of reproductive age and since most women are active during this phase of life, it is plausible to hypothesize that CPP, in addition to interfering in a negative manner with the personal, marital and social life of women [6] [7], may involve a significant impairment of their occupational performance, i.e., their ability to perform routines, roles and tasks in response to their external and internal environment.

Occupational therapy, mainly over the last decades, has focused on physical, psychosocial and environmental factors aggravated by pain, especially in the self-care, leisure and work spheres. Since the 1980 decade, programs of occupational training have proved to be effective in the counseling and rehabilitation of women with chronic pain [8]. And, within a multidisciplinary context, the Intion (https://www.iasp-pain.org/Education/Content.aspx?ItemNumber=1581). Twiddy et al. have reported that a multidisciplinary approach is effective in significantly improving the occupational performance measure of the CPP population [9]. The authors cited areas for improvement such as intimate relationships, establishing a routine, personal care and general activity. Nevertheless, to our knowledge, no objective or detailed data are available in the literature about the occupational performance of women with CPP, nor is there an objective detailed description of possible unassisted techniques to be practiced by these professionals.

Thus, the objective of the present study was to assess the satisfaction and occupational performance of women with CPP and to present coping strategies on the basis of a narrative review (comprehensive review) of unassisted interventions by occupational therapists as part of the multi-professional care for these patients.

\section{Methods}

A case-control study was conducted on 75 women of reproductive age older than 18 years from February 2014 to January 2015. The subjects were seen at the Chronic Pelvic Pain Center of the University Hospital, Ribeirão Preto Medical School, University of São Paulo, a regional reference center. Seventy-five apparently healthy women selected from those accompanying the patients were used as controls. No type of pairing was performed.

\subsection{Ethics}

All participants were individually informed about the objectives, relevance and methodology of the study. The principles of reliability of the data obtained, maintenance of autonomy of the participants, protected personal identification 
and beneficence of the purposes were respected and the subjects gave written informed consent to participate. The study was approved by the Ethics Committee of the institution (protocol $n^{\circ}$ 9091/2012).

\subsection{Eligibility}

Women of reproductive age, with no history of neoplasias or chronic diseases such as diabetes and hypertension, or of recent acute pain events, and receiving no treatment modality for their current condition were considered to be eligible for the study. All participants answered the questionnaires before any therapeutic measure was instituted. For the disease group of the study we considered women with noncyclic pain of six or more months' duration localized to the anatomic pelvis, or anterior abdominal wall below the umbilicus, and of sufficient severity to cause functional disability or to require medical care. Women with isolated dyspareunia or dysmenorrhea were not included. The control group of healthy women was recruited from subjects with the same sociodemographic characteristics as the patients, exclusively attending a primary health care unit of the Unified Health System of the country.

\subsection{Variables and Data Measurement}

An initial interview was held with each woman in a private room, during which all procedures were first explained. We then applied a semistructured questionnaire, including investigation about age, parity, marital relationship, schooling, professional activity, religion, race, abdominal surgery, age at menarche, body mass index, time and intensity of pain measured with a visual analogue scale. We also performed psychometric assessment using the Brazilian version of the Patient Health Questionnaire (PHQ) [10], of the Self-Reporting Questionnaire of Psychiatric Screening (SRQ) [11], and of the Tampa Scale of Kinesiophofobia (TSK) [12].

The main outcomes of occupational performance and satisfaction were assessed with the Canadian Occupational Performance Measure (COPM) [13], a validated instrument of broad applicability [14] consisting of three stages:

1) description of daily activities and occupations. In this stage the reported activities were assigned to the following categories and subcategories:

a) self-care: personal care (hygiene, eating habits, clothing), mobility (transfers, mobility inside and outside the home), independence outside the home (transportation, shopping, finances);

b) productivity: job (looking for and/or keeping employment, voluntary activities), household chores (cleaning, washing clothes, preparation of meals), duties or school activities (duties in addition to a job and household chores);

c) leisure: quiet recreation (hobbies, reading, handcraft, $\mathrm{TV}$, computer), active recreation (sports, excursions, trips), and socializing (visits, telephone calls, parties, letter writing);

2) scoring and hierarchization of the importance of the activities: the partici- 
pant scored the relevance of each activity on a $100 \mathrm{~mm}$ visual scale (ranging from "of no importance" to "extremely important"). According to the order of relevance, the subject was asked to choose three to five activities with higher scores;

3) classification of performance and satisfaction: for each chosen activity the participant quantitated her performance in it and her satisfaction with it also using a $100 \mathrm{~mm}$ visual scale (ranging from "unable to do" to "able to do extremely well" for performance, and "not satisfied" to extremely satisfied" for satisfaction). The final result of this evaluation considered the mean value of the sum of scores for performance and the sum of scores for satisfaction divided by the number of activities assessed.

\subsection{Data Bank}

The data obtained were recorded on a form specifically prepared for this purpose and transferred to the electronic data bank, managed in such a way as to guarantee confidentiality of the information and preservation of patient identity.

\subsection{Statistical Analysis}

Sample size was calculated in order to compare two means (two-sample, two-sided equality) by an online calculator (http://www.powerandsamplesize.com/). Based on a pilot sample of healthy subjects $(n=30)$, the parameters used were power of $90 \%$, type I error rate of 5\%, mean of performance/satisfaction of 9.6 , standard deviation of 3.75 , sampling ratio of 1 , and estimated significant difference of at least 2.0 points below the mean for the healthy group, i.e., a disease group mean of at least 7.6. Exploratory data analysis was carried out based on the means and standard deviations and the frequency distribution. The Fisher exact test was used to compare the frequencies of each quantitative variable of the study between groups and the Student t-test was used to compare the quantitative variables. The distribution of the data was checked using normalized graphs. Linear regression analysis was carried out to determine the effect of covariables in relation to the variables of interest only for the group of patient with CPP. The fit of the model was determined by residue analysis. All analyses were carried out with the aid of the SAS software, version 9.3, with the level of significance set at $5 \%$.

\subsection{Comprehensive Review}

Studies in English reporting the interventions of occupational therapists in adult subjects with non-oncologic chronic pain were considered eligible, regardless of sex or class of the population studied. Studies that used assistance technologies or that did not present or describe the technique used were not considered to be eligible. Review articles and guidelines were read in full but were not included in the analysis. All reference lists were explored in order to expand the search for information. 
The search was carried out in the Pubmed and Scopus databases using the following key words: ["occupational therapy" or "pacing" or "relax*" or "goal ${ }^{\star}$ " or "cognit" or "exerc*"] and ["chronic pain" or "persistent pain"]. In this step, we investigated whether the title and abstract contained the above key words. The search covered the period of the last 25 years (1994-2018). All articles selected were obtained in full and were evaluated independently by two authors (RVB and OBPN) and classified by the Jaddad criteria of quality [15]. Eventual doubts were resolved in a consensus meeting. A total of 264 articles were detected; 171 of them were not considered because they did not specify the professional involved in the intervention and 23 that were bibliographic reviews and/or citations were also excluded. Thus, 70 articles were selected and read in full. Of these, 66 were discarded, 2 of them because they were guidelines, 17 because they were bibliographic reviews and 47 because they involved a multidisciplinary team (these last articles were discarded because they did not describe the type of intervention used by occupational therapy within the multidisciplinary approach). Only four articles were considered eligible [16] [17] [18] [19], as listed in Table 1.

\section{Results}

The characterization of the series is presented in Table 2.

Women with CPP had significantly lower performance and satisfaction scores than healthy women regarding all categories presented, i.e., self-care, productivity and leisure (Table 3). A significantly higher proportion of women with CPP attributed more importance to functional mobility than healthy ones $(18.7 \%$ versus $12.0 \%$, respectively) and to household chores (38.7\% versus $17.3 \%$, respectively). On the other hand, sick women attributed lower importance to school activities or duties other than work or domestic activities than controls ( $48.0 \%$ versus $77.3 \%$, respectively) (Table 4 ).

A direct correlation was detected between low satisfaction scores and the presence of CPP, regardless of ethnicity, marital status, schooling, or PHQ and

Table 1. Information contained in comprehensive review articles.

\begin{tabular}{|c|c|c|c|c|c|c|c|}
\hline Authors & Country & Journal & Year & Intervention & Follow-up & Instruments & Score \\
\hline Krischak et al. & Germany & $\begin{array}{l}\text { J Shoulder } \\
\text { Elbow }\end{array}$ & 2013 & $\begin{array}{l}\text { Functional } \\
\text { restoration }\end{array}$ & 8 weeks & $\begin{array}{c}\text { Visual analogue Scale (VAS) } \\
\text { EuroQol questionnaire (EQ-5D) }\end{array}$ & 5 \\
\hline Murphy et al. & USA & $\begin{array}{l}\text { Am J Occup } \\
\text { Ther }\end{array}$ & 2010 & Pacing & 10 weeks & $\begin{array}{c}\text { Western Ontario and McMaster Universities } \\
\text { Osteoarthritis Index (WOMAC) } \\
\text { Brief Fatigue Inventory (BFI) } \\
\text { Six Minute Walk Test } \\
\text { Timed Up and Go Test } \\
\text { Actiwatch-Score }\end{array}$ & 4 \\
\hline $\begin{array}{l}\text { Park and } \\
\text { Sonty }\end{array}$ & USA & J Pain & 2010 & Coping & 1 interview & $\begin{array}{c}\text { Treatment Outcomes in Pain Survey (TOPS) } \\
\text { Numerical rating scale (NRS) }\end{array}$ & 1 \\
\hline Persson et al. & Sweden & $\begin{array}{l}\text { Scand J } \\
\text { Occup Ther }\end{array}$ & 2011 & Coping & 1 interview & Interview with narrative structure & 2 \\
\hline
\end{tabular}

Note: Score classified by Jaddad criteria of quality. 
Table 2. Characterization of the casuistic series.

\begin{tabular}{|c|c|c|c|}
\hline & $\begin{array}{l}\text { Healthy } \\
(\mathrm{n}=75)\end{array}$ & $\begin{array}{c}\text { CPP } \\
(n=75)\end{array}$ & $\mathrm{p}$ \\
\hline Age (mean \pm sd) & $35.5 \pm 4.3$ & $34.6 \pm 7.1$ & 0.7320 \\
\hline Stable union (n, \%) & $46(61.3)$ & $54(72.0)$ & 0.1659 \\
\hline Schooling (n, \%) & & & $<0.0001$ \\
\hline$<8 \mathrm{y}$ & $7(10.0)$ & $19(25.3)$ & \\
\hline 8 to $11 y$ & $10(13.3)$ & $24(32.4)$ & \\
\hline 12 to $15 y$ & $20(26.7)$ & $23(31.1)$ & \\
\hline $16+y$ & $38(50.0)$ & $9(12.2)$ & \\
\hline Paid work activity (n, \%) & $15(20.0)$ & $18(24.0)$ & 0.5543 \\
\hline Religion (n, \%) & & & 0.0256 \\
\hline Catholicism & $39(51.7)$ & $29(39.1)$ & \\
\hline Atheism & $7(10.0)$ & $2(2.8)$ & \\
\hline Others & $29(38.3)$ & $44(58.7)$ & \\
\hline Self-declared color (n, \%) & & & 0.2504 \\
\hline White & $63(85.2)$ & $69(91.8)$ & \\
\hline Black & $6(8.2)$ & $12(17.6)$ & \\
\hline Menarche (mean \pm sd) & 13.0 & 12.5 & 0.3247 \\
\hline Parity (median, range) & $1(0-4)$ & $1(0-6)$ & 0.3211 \\
\hline Abdominal surgery $(\mathrm{n}, \%)$ & $9(12.2)$ & $56(75.3)$ & $<0.0001$ \\
\hline Dysmenorrhea (n, \%) & $0(0.0)$ & $39(52.0)$ & $<0.0001$ \\
\hline Dyspareunia (n, \%) & $0(0.0)$ & $32(42.5)$ & $<0.0001$ \\
\hline PHQ-4 (mean $\pm \mathrm{sd})$ & $2.8 \pm 2.4$ & $5.6 \pm 3.9$ & $<0.0001$ \\
\hline PHQ-4 $\geq 5$ (n, \%) & $15(25.0)$ & $40(54.8)$ & 0.0004 \\
\hline SRQ (mean \pm sd) & $4.5 \pm 2.8$ & $8.4 \pm 4.9$ & $<0.0001$ \\
\hline $\mathrm{SRQ} \geq 8(\mathrm{n}, \%)$ & $12(20.0)$ & $40(54.8)$ & $<0.0001$ \\
\hline TSK (mean \pm sd) & - & $44.8 \pm 9.1$ & - \\
\hline Duration of pain in months(mean \pm sd) & - & $99.8 \pm 59.8$ & - \\
\hline Pain intensity in millimeters (mean $\pm s d)$ & - & $69.6 \pm 22.1$ & - \\
\hline
\end{tabular}

Note: CPP: chronic pelvic pain; Intensity of pain evaluated by visual analogue scale; sd: standard deviation.

SRQ scores. We also identified a consistent, independent and indirect correlation between kinesiophobia scores and leisure satisfaction ( $\mathrm{t}$ statistic $=-2.5$ and $\mathrm{p}=0.04$ ), as well as with total scores of satisfaction ( $\mathrm{t}$ statistic $=-3.1$ and $\mathrm{p}<$ 0.01). Similarly, we observed an independent and indirect correlation between performance scores and presence of CPP for all categories. However, kinesiophobia was not correlated to performance, despite being important for some categories of satisfaction (Table 5).

Our comprehensive review identified three objective intervention alternatives, all of them finally culminating with a coping process: the practice of exercise for functional reestablishment [16], pacing [17], and coping itself [18] [19]. Krischak et al.'s paper [16] prospectively reported the effect of a supervised 
Table 3. Performance and satisfaction score measured with the COPM scale.

\begin{tabular}{cccc}
\hline & Healthy & CPP & $p$ \\
\hline Performance & & & \\
\hline Self-care & $9.8 \pm 0.6$ & $6.3 \pm 2.8$ & $<0.0001$ \\
Productivity & $9.6 \pm 0.6$ & $5.4 \pm 3.0$ & $<0.0001$ \\
Leisure & $9.6 \pm 0.9$ & $4.8 \pm 3.1$ & $<0.0001$ \\
Total score & $9.8 \pm 1.2$ & $5.4 \pm 2.4$ & $<0.0001$ \\
\hline Satisfaction & & & $<0.0001$ \\
Self-care & $9.7 \pm 0.76$ & $4.7 \pm 3.1$ & $<0.0001$ \\
Productivity & $9.6 \pm 0.8$ & $4.2 \pm 3.0$ & $<0.0001$ \\
Leisure & $9.5 \pm 1.0$ & $4.1 \pm 3.1$ & $<0.0001$ \\
Total score & $9.6 \pm 0.7$ & $4.4 \pm 2.4$ & . \\
\hline
\end{tabular}

Note: COPM: Canadian Occupational Performance Measure; CPP: chronic pelvic pain. Analysis performed by the Wilcoxon (Kruskal-Wallis) test, and confirmed by linear regression, considering marital status, paid work activity, schooling, religion, abdominal surgery, and age.

Table 4. List of activates to which the participants attributed higher importance.

\begin{tabular}{cccc}
\hline & $\begin{array}{c}\text { Healthy } \\
(\mathrm{n}=75)\end{array}$ & $\begin{array}{c}\text { CPP } \\
(\mathrm{n}=75)\end{array}$ & $\mathrm{p}$ \\
\hline Self-care, n (\%) & $69(92.0)$ & $61(81.3)$ & 0.055 \\
Personal care & $65(86.7)$ & $54(72.0)$ & 0.058 \\
Functional mobility & $9(12.0)$ & $14(18.7)$ & 0.00013 \\
Independence outside the home & $9(12.0)$ & $6(8.0)$ & 0.199 \\
Productivity, n (\%) & $68(90.7)$ & $64(85.3)$ & 0.315 \\
Job & $30(40.0)$ & $26(34.7)$ & 0.7297 \\
Household chores & $13(17.3)$ & $29(38.7)$ & 0.0001 \\
Duties or school activities & $58(77.3)$ & $36(48.0)$ & 0.132 \\
Leisure n (\%) & $63(84.0)$ & $69(92.0)$ & 0.2252 \\
Quiet recreation & $21(28.0)$ & $29(38.7)$ & 0.6219 \\
Active recreation & $31(41.3)$ & $35(46.7)$ & 0.6219 \\
Socializing & $40(53.3)$ & $44(58.7)$ &
\end{tabular}

Note: CPP: chronic pelvic pain.

occupational physical therapy protocol versus written home exercise guidelines on 43 patients with unilateral atraumatic rotator cuff tears, randomly allocated to the intervention groups. They observed that clinical improvement occurred in approximately two-thirds of the patients, regardless of the intervention. However, they also observed an improvement in the quality of life scores among those patients who did the intervention at home without supervision. Murphy et al.'s paper [17] reported a study with 32 subjects with osteoarthritis of the knee or hip who were randomized to two pacing interventions. One group received 
Table 5. Linear regression model used to determine the effect of the covariables on occupational satisfaction and performance of women with chronic pelvic pain.

\begin{tabular}{|c|c|c|c|c|c|c|c|}
\hline & $\begin{array}{c}\text { Marital } \\
\text { status }\end{array}$ & Job & Color & PHQ & SRQ & TSK & $\mathrm{CPP}$ \\
\hline \multicolumn{8}{|l|}{ Satisfaction } \\
\hline Self-care & $\begin{array}{c}\text { [0.500] } \\
0.615\end{array}$ & $\begin{array}{c}{[-0.140]} \\
0.886\end{array}$ & $\begin{array}{c}{[-0.780]} \\
0.436\end{array}$ & $\begin{array}{c}{[-0.290]} \\
0.770\end{array}$ & $\begin{array}{c}{[-0.560]} \\
0.579\end{array}$ & $\begin{array}{c}{[-1.950]} \\
0.053\end{array}$ & $\begin{array}{c}{[-8.070]} \\
<0.0001\end{array}$ \\
\hline Productivity & $\begin{array}{c}{[0.270]} \\
0.788\end{array}$ & $\begin{array}{c}{[1.330]} \\
0.185\end{array}$ & $\begin{array}{c}{[0.980]} \\
0.328\end{array}$ & $\begin{array}{c}{[-0.500]} \\
0.619\end{array}$ & $\begin{array}{c}{[0.530]} \\
0.594\end{array}$ & $\begin{array}{c}{[-1.880]} \\
0.062\end{array}$ & $\begin{array}{c}{[-9.620]} \\
<0.0001\end{array}$ \\
\hline Leisure & $\begin{array}{c}{[1.800]} \\
0.074\end{array}$ & $\begin{array}{c}{[2.060]} \\
0.042\end{array}$ & $\begin{array}{c}{[-0.400]} \\
0.690\end{array}$ & $\begin{array}{c}{[1.170]} \\
0.245\end{array}$ & $\begin{array}{c}{[-0.370]} \\
0.711\end{array}$ & $\begin{array}{c}{[-2.510]} \\
0.013\end{array}$ & $\begin{array}{c}{[-9.020]} \\
<0.0001\end{array}$ \\
\hline Total score & $\begin{array}{c}{[0.140]} \\
0.890\end{array}$ & $\begin{array}{c}{[1.930]} \\
0.055\end{array}$ & $\begin{array}{c}{[0.540]} \\
0.593\end{array}$ & $\begin{array}{c}{[-0.040]} \\
0.971\end{array}$ & $\begin{array}{c}{[-0.930]} \\
0.354\end{array}$ & $\begin{array}{c}{[-3.070]} \\
0.003\end{array}$ & $\begin{array}{c}{[-11.310]} \\
<0.0001\end{array}$ \\
\hline Performance & & $\begin{array}{c}{[0.540]} \\
0.593\end{array}$ & $\begin{array}{c}{[0.540]} \\
0.593\end{array}$ & & & & \\
\hline Self-care & $\begin{array}{c}{[0.840]} \\
0.402\end{array}$ & $\begin{array}{c}{[0.390]} \\
0.696\end{array}$ & $\begin{array}{c}{[-0.880]} \\
0.381\end{array}$ & $\begin{array}{c}{[-0.350]} \\
0.730\end{array}$ & $\begin{array}{c}{[0.730]} \\
0.466\end{array}$ & $\begin{array}{c}{[-1,790]} \\
0.077\end{array}$ & $\begin{array}{c}{[-6.200]} \\
<0.0001\end{array}$ \\
\hline Productivity & $\begin{array}{c}{[-0.190]} \\
0.847\end{array}$ & $\begin{array}{c}{[0.540]} \\
0.588\end{array}$ & $\begin{array}{c}{[0.550]} \\
0.585\end{array}$ & $\begin{array}{c}{[-0.560]} \\
0.576\end{array}$ & $\begin{array}{c}{[-1.600]} \\
0.112\end{array}$ & $\begin{array}{c}{[-1.120]} \\
0.266\end{array}$ & $\begin{array}{c}{[-7.360]} \\
<0.0001\end{array}$ \\
\hline Leisurer & $\begin{array}{c}{[1.600]} \\
0.112\end{array}$ & $\begin{array}{c}{[0.080]} \\
0.935\end{array}$ & $\begin{array}{c}{[-1.190]} \\
0.238\end{array}$ & $\begin{array}{c}{[-1.170]} \\
0.245\end{array}$ & $\begin{array}{c}{[1.640]} \\
0.103\end{array}$ & $\begin{array}{c}{[-0.320]} \\
0.752\end{array}$ & $\begin{array}{c}{[-8.810]} \\
<0.0001\end{array}$ \\
\hline Total score & $\begin{array}{c}{[-0.340]} \\
0.738\end{array}$ & $\begin{array}{c}{[0.750]} \\
0.453\end{array}$ & $\begin{array}{c}{[-0.180]} \\
0.854\end{array}$ & $\begin{array}{c}{[-0.210]} \\
0.837\end{array}$ & $\begin{array}{c}{[-0.760]} \\
0.450\end{array}$ & $\begin{array}{c}{[-1.790]} \\
0.076\end{array}$ & $\begin{array}{c}{[-9.000]} \\
<0.0001\end{array}$ \\
\hline
\end{tabular}

Note: The model was adjusted by residue analysis, considering $5 \%$ as significant. T statistic is given in brackets and p follows; PHQ: Patient Health Questionnaire; SRQ: Self-Reporting Questionnaire of Psychiatric Screening; TSK: Tampa Scale of Kinesiophofobia.

general instructions on activity pacing such as pre-planning activities, alternating activity with rest before exacerbation of symptoms, and the other group received personalized guidance based on detailed data on the relationship between developed activity and symptoms. They observed that the second group showed considerable improvement of fatigue. However, there was no significant impact on the control of clinical pain in any of the groups. Park and Sonty's study [18] retrospectively assessed 106 subjects with non-cancer chronic pain. They observed that there was a direct correlation between positive emotions and coping efficacy considering the interference of pain in the subject's social activities. Persson et al.'s study [19], in turn, selected 12 subjects with chronic pain and performed a qualitative study based on a narrative interview. They noted that when coping occupations were pleasurable and appreciated by the subjects, the pain was commonly shifted out of focus.

\section{Discussion}

The present study shows that performance and satisfaction scores for activities judged to be important are considerably lower among women with CPP than among healthy women, even when weighted according to the influence of other variables. Although never before reported for this population of women, this significant occupational impairment was expected to be similar to that previously 
observed among other subjects with signs and symptoms of persistent pain [20] [21] [22] [23]. Many reasons may be behind this fact. The first and most obvious reason is the limitation of daily activity due to pain itself and the underlying disease. However, another element with a potential role in determining this limitation is coping [24] [25]. The fact that women with CPP attribute less importance to the self-care category unfortunately is not explained by our study. However, the higher prevalence of stigmatization and poor self-esteem is usual among chronic pain patients [26]. Furthermore, the scores of general and psychological symptoms observed in our series reflected by PHQ-4 and SRQ scores may be an indirect evidence of this. In addition, it is known that the presence of symptoms of depression, anxiety, catastrophization, low self-esteem, negative emotions, poor adaptation, social isolation, loss of identity [27] [28] and, probably, genetic inheritance [29] may compromise the ability of the patient to feel able to deal with the situation, that is, to control or adapt to the symptoms. Anyway, our study has some limitations that are inherent to the methodological design. Although plausible, it is impossible to define a causality association between CPP and occupational performance/satisfaction. Ideally, a prospective study would bring more valuable information about the actual impact of the clinical condition in determining low levels of satisfaction and performance. Nevertheless, the cost and time spent with this design would not be feasible without the existence of prior information such as that provided by our study.

As identified in our comprehensive review, the coping ability has a beneficial effect on the quality of life of patients with chronic pain, although it is not necessarily related to the improvement of clinical pain. There is no uniform conceptualization of coping. It is a complex process defined as thoughts and actions on which the persons focus their efforts in order to manage pain on a daily basis [30]. Although some authors state that coping is a confuse concept [31], a considerable diversity of strategies, instruments and questionnaires have been extensively described in the pertinent literature [32]. This complexity is due, at least in part, to the fact that coping strategies are multidimensional, involving cognitive, affective, behavioral and physiological human functioning. In general, coping consists of a response to stress and may be both voluntary or involuntary. The first response is a search for social support or the anticipation and prevention of stressors, while the second is also called defense. Within this involuntary group it is also possible to define at least a dichotomization of the characteristics: a set of "mature" or "adaptive" elements such as fever, tachycardia, coughing, muscle contracture, sublimation, mood change, and a set of "pathological", "immature" or "maladaptative" elements that seem to be more damaging, particularly when seen as elements external to the subject, such as fantasies, self-aggression, isolation, phobia, somatization, and rumination [33]. Maladaptive coping may also paradoxically culminate with reverberation of the perception of symptoms and a sensation of impotence in the face of the problem [34]. Unfortunately, the chemical processes and the neuronal pathways involved in 
these defense and coping processes have not been identified. Furthermore, coping is directly associated with resilience [35]. And women with chronic pain, age close to 40 years, 9 to 12 years of schooling, and inserted in the labor market constitute a profile of patients classified as potentially "non resilient" [36]. This profile is very similar to that of our population of women with chronic pelvic pain.

Another element identified in our comprehensive review was pacing which is also a coping strategy widely recommended for patients with persistent pain within a multidisciplinary context. However, a lack of conceptual clarity implies restriction of the application of the method and limits the execution of rigorous studies [37]. The definition that seems most adequate to us is the following "Pacing is an active self-management strategy whereby individuals learn to balance time spent on activity and rest for the purpose of achieving increased function and participation in meaningful activities" [38]. This article cites important and highly illustrative cases of how the technique can be applied in practice. The establishment of goals and tasks to be carried out with intervals of rest or leisure between them can help the patients to program their daily activities and to carry them out in a more effective manner and with greater well being and quality of life. Some strategies are frequently applied spontaneously by the patients themselves, taking into account their life context. However, some of them only become effective if set up and/or accompanied by professional help. In any case, it is not possible to separate coping and resilience from the experiences of an individual and from his family, social, cultural, educational and religious relationships [39].

In the last years, neuroscience has been increasingly demonstrating the overlapping and in dissociation of physical pain and social pain. The social medium can increase the vulnerability of an individual to pain and also compromise his resilience in the face of the problem. Although social support is important to promote effective adaptation to pain, the social intelligence and resilience of an individual are of fundamental importance [40]. Unfortunately, we identified only a few papers whose key professional was an occupational therapist. We believe that these professionals can direct the preparation of a protocol of objective activity. The professional can acts as a mediator or moderator and helps the subjects to identify stressful events early, consequently helping with the construction of active strategies for the prevention and elimination or minimization of damage.

\section{Conclusion}

Women with CPP exhibit significant impairment of satisfaction and occupational performance in all categories considered. Coping is an important strategy that can be proposed and supervised by occupational therapists within a multidisciplinary context dealing with this population. However, the resilience of the subject is fundamental for the success of the strategy. 


\section{Conflicts of Interest}

The authors declare no conflicts of interest regarding the publication of this paper.

\section{References}

[1] Tsang, A., Von Korff, M., Lee, S., Alonso, J., Karam, E., Angermeyer, M.C., et al. (2008) Common Chronic Pain Conditions in Developed and Developing Countries: Gender and Age Differences and Comorbidity with Depression-Anxiety Disorders. Journal of Pain, 9, 883-891. https://doi.org/10.1016/j.jpain.2008.05.005

[2] ACOG Committee on Practice Bulletins-Gynecology (2004) ACOG Practice Bulletin No. 51. Chronic Pelvic Pain. Obstetrics \& Gynecology, 103, 589-605. https://doi.org/10.1097/00006250-200403000-00045

[3] Latthe, P., Latthe, M., Say, L., Gülmezoglu, M. and Khan, K.S. (2006) WHO Systematic Review of Prevalence of Chronic Pelvic Pain: A Neglected Reproductive Health Morbidity. BMC Public Health, 6, 177.

https://doi.org/10.1186/1471-2458-6-177

[4] de OG da Silva, G.P., do Nascimento, A.L., Michelazzo, D., Alves Junior, F.F., Rocha, M.G., Silva, J.C.R.E., et al. (2011) High Prevalence of Chronic Pelvic Pain in Women in Ribeirão Preto, Brazil and Direct Association with Abdominal Surgery. Clinics, 66, 1307-1312.

[5] Coelho, L.S.C., Brito, L.M.O., Chein, M.B.C., Mascarenhas, T.S., Costa, J.P.L., Nogueira, A.A., et al. (2014) Prevalence and Conditions Associated with Chronic Pelvic Pain in Women from São Luís, Brazil. Brazilian Journal of Medical and Biological Research, 47, 818-825. https://doi.org/10.1590/1414-431X20143710

[6] Romão, A.P.M.S., Gorayeb, R., Romão, G.S., Poli-Neto, O.B., Dos Reis, F.J.C., Rosa-E-Silva, J.C., et al. (2011) Chronic Pelvic Pain: Multifactorial Influences. Journal of Evaluation in Clinical Practice, 17, 1137-1139.

[7] Souza, P.P., Salata Romão, A., Rosa-E-Silva, J.C., Candido Dos Reis, F., Nogueira, A.A. and Poli-Neto, O.B. (2011) Qualitative Research as the Basis for a Biopsychosocial Approach to Women with Chronic Pelvic Pain. Journal of Psychosomatic Obstetrics \& Gynecology, 32, 165-172.

[8] Robinson, K., Kennedy, N. and Harmon, D. (2011) Review of Occupational Therapy for People with Chronic Pain. Australian Occupational Therapy Journal, 58, 74-81. https://doi.org/10.1111/j.1440-1630.2010.00889.x

[9] Twiddy, H., Lane, N., Chawla, R., Johnson, S., Bradshaw, A., Shaireen, A. and Mawdsley, L. (2015) The Development and Delivery of a Female Chronic Pelvic Pain Management Programme: A Specialised Interdisciplinary Approach. British Journal of Pain, 9, 233-240. https://doi.org/10.1177/2049463715584408

[10] de Lima Osório, F., Vilela Mendes, A., Crippa, J.A. and Loureiro, S.R. (2009) Study of the Discriminative Validity of the PHQ-9 and PHQ-2 in a Sample of Brazilian Women in the Context of Primary Health Care. Perspectives in Psychiatric Care, 45, 216-227. https://doi.org/10.1111/j.1744-6163.2009.00224.x

[11] Mari, J.J. and Williams, P. (1986) A Validity Study of a Psychiatric Screening Questionnaire (SRQ-20) in Primary Care in the City of Sao Paulo. The British Journal of Psychiatry, 148, 23-26. https://doi.org/10.1192/bjp.148.1.23

[12] de Souza, F.S., da Silva Marinho, C., Siqueira, F.B., Maher, C.G. and Costa, L.O.P. (2008) Psychometric Testing Confirms that the Brazilian-Portuguese Adaptations, the Original Versions of the Fear-Avoidance Beliefs Questionnaire, and the Tampa 
Scale of Kinesiophobia Have Similar Measurement Properties. Spine, 33, 1028-1033. https://doi.org/10.1097/BRS.0b013e31816c8329

[13] Carswell, A., McColl, M.A., Baptiste, S., Law, M., Polatajko, H. and Pollock, N. (2004) The Canadian Occupational Performance Measure: A Research and Clinical Literature Review. Canadian Journal of Occupational Therapy, 71, 210-222. https://doi.org/10.1177/000841740407100406

[14] Nieuwenhuizen, M.G., de Groot, S., Janssen, T.W.J., van der Maas, L.C.C. and Beckerman, H. (2014) Canadian Occupational Performance Measure Performance Scale: Validity and Responsiveness in Chronic Pain. Journal of Rehabilitation Research and Development, 51, 727-746. https://doi.org/10.1682/JRRD.2012.12.0221

[15] Adad, A.R., Moore, R.A., Carroll, D., Jenkinson, C., Reynolds, D.J., Gavaghan, D.J., et al. (1996) Assessing the Quality of Reports of Randomized Clinical Trials: Is Blinding Necessary? Controlled Clinical Trials, 17, 1-12.

https://doi.org/10.1016/0197-2456(95)00134-4

[16] Krischak, G., Gebhard, F., Reichel, H., Friemert, B., Schneider, F., Fisser, C., et al. (2013) A Prospective Randomized Controlled Trial Comparing Occupational Therapy with Home-Based Exercises in Conservative Treatment of Rotator Cuff Tears. Journal of Shoulder and Elbow Surgery, 22, 1173-1179. https://doi.org/10.1016/j.jse.2013.01.008

[17] Murphy, S.L., Lyden, A.K., Smith, D.M., Dong, Q. and Koliba, J.F. (2010) Effects of a Tailored Activity Pacing Intervention on Pain and Fatigue for Adults with Osteoarthritis. American Journal of Occupational Therapy, 64, 869-876. https://doi.org/10.5014/ajot.2010.09198

[18] Park, S.H. and Sonty, N. (2010) Positive Affect Mediates the Relationship between Pain-Related Coping Efficacy and Interference in Social Functioning. Journal of Pain, 11, 1267-1273. https://doi.org/10.1016/j.jpain.2010.02.023

[19] Persson, D., Andersson, I. and Eklund, M. (2011) Defying Aches and Revaluating Daily Doing: Occupational Perspectives on Adjusting to Chronic Pain. Scandinavian Journal of Occupational Therapy, 18, 188-197. https://doi.org/10.3109/11038128.2010.509810

[20] Silvemark, A.J., Källmén, H., Portala, K. and Molander, C. (2008) Life Satisfaction in Patients with Long-Term Non-Malignant Pain-Relation to Demographic Factors and Pain Intensity. Disability and Rehabilitation, 30, 1929-1937. https://doi.org/10.1080/09638280701748773

[21] McNamee, P. and Mendolia, S. (2014) The Effect of Chronic Pain on Life Satisfaction: Evidence from Australian Data. Social Science \& Medicine, 121, 65-73. https://doi.org/10.1016/j.socscimed.2014.09.019

[22] Perneros, G., Tropp, H. and Sandqvist, J. (2014) Evaluation of Occupational Performance and Pain Intensity: Before and after Back Surgery and Rehabilitation. Scandinavian Journal of Occupational Therapy, 21, 69-81.

[23] Strand, V., Wright, G.C., Bergman, M.J., Tambiah, J. and Taylor, P.C. (2015) Patient Expectations and Perceptions of Goal-Setting Strategies for Disease Management in Rheumatoid Arthritis. The Journal of Rheumatology, 42, 2046-2054. https://doi.org/10.3899/jrheum.140976

[24] Barry, L.C., Kerns, R.D., Guo, Z., Duong, B.D., Iannone, L.P. and Carrington Reid, M. (2004) Identification of Strategies Used to Cope with Chronic Pain in Older Persons Receiving Primary Care from a Veterans Affairs Medical Center. Journal of the American Geriatrics Society, 52, 950-956.

https://doi.org/10.1111/j.1532-5415.2004.52263.x 
[25] Reid, M., Barry, L., Kerns, R., Duong, B. and Concato, J. (2002) Coping Strategies and Their Associations with Levels of Disability or Pain, among Older Veterans Receiving Primary Care. Journal of Clinical Epidemiology, 55, 629. https://doi.org/10.1016/S0895-4356(02)00420-1

[26] Hegarty, D. (2014) Prevalence of Stigmatization and Poor Self-Esteem in Chronic Pain Patients. Journal of Pain and Relief, 3, 136.

[27] Leung, L. (2012) Pain Catastrophizing: An Updated Review. Indian Journal of Psychological Medicine, 34, 204-217. https://doi.org/10.4103/0253-7176.106012

[28] Juth, V., Smyth, J.M. and Santuzzi, A.M. (2008) How Do You Feel? Self-Esteem Predicts Affect, Stress, Social Interaction, and Symptom Severity during Daily Life in Patients with Chronic Illness. Journal of Health Psychology, 13, 884-894. https://doi.org/10.1177/1359105308095062

[29] Dunn, S.H. and Conley, Y.P. (2015) A Systematic Review of Genetic Influences on Coping. Biological Research for Nursing, 17, 87-93. https://doi.org/10.1177/1099800414527340

[30] Zeidner, M. and Endler, N.S. (1996) Handbook of Coping: Theory, Research, Applications. Wiley, Hoboken.

[31] Van Damme, S., Crombez, G. and Eccleston, C. (2008) Coping with Pain: A Motivational perspective. Pain, 139, 1-4. https://doi.org/10.1016/j.pain.2008.07.022

[32] Peres, M.F.P. and Lucchetti, G. (2010) Coping Strategies in Chronic Pain. Current Pain and Headache Reports, 14, 331-338. https://doi.org/10.1007/s11916-010-0137-3

[33] Vaillant, G.E. (2011) Involuntary Coping Mechanisms: A Psychodynamic Perspective. Dialogues in Clinical Neuroscience, 13, 366-370.

[34] Thompson, R.J., Mata, J., Jaeggi, S.M., Buschkuehl, M., Jonides, J. and Gotlib, I.H. (2010) Maladaptive Coping, Adaptive Coping, and Depressive Symptoms: Variations across Age and Depressive State. Behaviour Research and Therapy, 48, 459-466. https://doi.org/10.1016/j.brat.2010.01.007

[35] Sturgeon, J.A. and Zautra, A.J. (2013) Psychological Resilience, Pain Catastrophizing, and Positive Emotions: Perspectives on Comprehensive Modeling of Individual Pain Adaptation. Current Pain and Headache Reports, 17, 317. https://doi.org/10.1007/s11916-012-0317-4

[36] Souza, I., Vasconcelos, A.G.G., Caumo, W. and Baptista, A.F. (2017) Resilience Profile of Patients with Chronic Pain. Cadernos de Saúde Pública, 33, e00146915.

[37] Gill, J.R. and Brown, C.A. (2009) A Structured Review of the Evidence for Pacing as a Chronic Pain Intervention. European Journal of Pain, 13, 214-216. https://doi.org/10.1016/j.ejpain.2008.03.011

[38] Jamieson-Lega, K., Berry, R. and Brown, C.A. (2013) Pacing: A Concept Analysis of the Chronic Pain Intervention. Pain Research and Management, 18, 207-213. https://doi.org/10.1155/2013/686179

[39] Rippentrop, E.A., Altmaier, E.M., Chen, J.J., Found, E.M. and Keffala, V.J. (2005) The Relationship between Religion/Spirituality and Physical Health, Mental Health, and Pain in a Chronic Pain Population. Pain, 116, 311-321. https://doi.org/10.1016/j.pain.2005.05.008

[40] Sturgeon, J.A. and Zautra, A.J. (2016) Social Pain and Physical Pain: Shared Paths to Resilience. Pain Management, 6, 63-74. https://doi.org/10.2217/pmt.15.56 